\title{
SOME RELATIONSHIPS BETWEEN PERSONALITY AND BODY CHEMISTRY *
}

\author{
$\mathrm{Br}$ \\ GILBERT J. RICH, Chicago \\ INTRODUGTION
}

Witu the tremendous advance of biochemistry in recent years, physiology has found it advantageous to direct both its methods of research and its explanatory concepts along chemical lines. Physiological psychology has been somewhat slower to adopt this new point of view. But a perusal of the literature of the past decade soon shows that it is gradually falling into line. There has been a slowly increasing number of studies relating various aspects of behaviour to chemical changes within the body. Research in this field has been following, in the main, four principal directions: (1) endocrine research, which includes extirpation and feeding experiments as well as the data derived from the endocrinopathies ; $(2)$ the effects of various types of activity, intellectual, volitional or emotional, upon metabolism, secretion and body constitution; (3) the effects of drugs and chemicals upon behaviour ; and (4) studies of the correlation between the chemistry of the body, including its excretions, and those patterns of total behaviour which we call personality.

It is with this fourth type of psychobiochemical study that this paper is concerned. Although its beginnings can readily be traced back a quarter of a century (and even older investigations pointing out the direction of future endeavour are to be found). the real development of the field has been within our own time. Like so many other branches of human biology, the first impetus seems to have come from those who work with disease. For a number of years there has been considerable interest in the differential chemistry of those gross deviations of personality, the psychoses and neuroses. More recently attempts have been made to extend these investigations to the study of personality variations which are within the range of normality.

\section{ACID-BASE BALANCE}

One of the most fruitful fields of research has been the acid-base balance of the body. Ludlum was among the first to arouse interest in its possibilities. After he and his co-workers had found that there was a differentiation between excited and confused types in acute insanity on the basis of the reaction of the secretions and excretions of the body, they proceeded, perhaps somewhat

* Studies from the Institute for Juvenile Research, Chicago. Series C. No. 203. A paper read at the meeting of Section $N$ (Medical Sciences) of the American Association for the Advancement of Science, New Orleans, December 30, 1931. 
prematurely, to relate gross neuromuscular symptom-pictures to the two types. 1,2,3.4 The theoretical implications are both suggestive and stimulating, even though factual data are absent.

Another series of observations bearing upon the problem has come from the Psychological Clinic at Philadelphia. Starr, ${ }^{5}$ who was the pioneer in this work, was able to show a marked difference in the hydrogen-ion content of saliva as between the so-called 'psychopathic' and 'sub-breather' types of stammerer, with a change in the saliva of the latter as he was freed under treatment from the acidosis due to the defective respiratory elimination of carbon dioxide. Later, it was found simpler to study the carbon-dioxide content of alveolar air, and similar results were obtained. ${ }^{6}$ In clinic patients other than stammerers, similar relationships have been found. ${ }^{7}$ Children who were apathetic were found to be mildly acidotic, due to inefficient respiratory elimination.

This point of view has been further emphasized by a recent group of studies from the laboratory of the London County Asylums. 8,9,10,11 The workers there find evidence of a rather definite disturbance in the acid-base equilibrium in psychotics. The normal tides in urinary excretion following the ingestion of acid or alkali are absent in these patients, who tend to maintain a flat level of urinary acidity, or to reverse the normal tides. In melancholics the urine tends to a constant acidity, with low alkali reserve of the blood. They have come to the conclusion that these abnormalities are due to inadequacy of the respiratory, rather than of the urinary, mechanism for acid-base regulation. In support of this contention it is shown that when 2 per cent. of carbon dioxide is breathed the increase in respiratory activity so noticeable in the normal subject is absent in the psychotic. ${ }^{12}$ Moreover, the administration of sodium bicarbonate causes increased urinary alkalinity in both types of subject, but the psychotic fails to show the normal curve for the rise and fall of the carbon dioxide content of alveolar air. These results tend to be somewhat confusing, however, because various types of psychoses are thrown together to form a non-homogeneous group.

In our own studies, we have worked with individuals who were, in general, within the range of normality. Here the differentiation of personality patterns has depended not upon the gross distinctions of mental disease, but upon the finer, and therefore less accurately determinable, gradations measured by a rating scale. We now have at hand ample data to show that, even with the crude procedures employed, there is a definite positive correlation between emotional excitability and relative alkalinity of the saliva. ${ }^{13,14}$ The more excitable individual tends to have a less acid saliva than does the calm and apathetic person. The same tendency is also evident in determinations of urinary acidity. The apathetic individual excretes by this channel more acid than does the emotionally excitable person.

So far the data all point in the same direction. The evidence may be summed up as showing that in the gross personality-deviations of mental 
disease there is some disturbance of the acid-base balance, and that, by and large, lowered acidity tends to be associated with the more active states and heightened acidity with the more apathetic conditions.

But a seeming exception is at once apparent. The effects of carbon dioxide inhalation upon catatonic patients are well-known. We may at once ask how it is that, if carbon dioxide retention is associated with body acidity and emotional dullness, the inhalation of large amounts of this gas causes the catatonic or postencephalitic patient to become more active. If, however, one examines further, it is apparent that during the experimental inhalation there are several other factors at work. One is the presence of oxygen to the extent of a very high partial pressure with, as Freeman ${ }^{15}$ points out, increased oxidative processes in the brain. Another is the rapid respiratory rate, which creates a situation quite different from that which exists when an individual is respiratorily sluggish and therefore retains carbon dioxide. Moreover, similar effects with respect to activation of the patient can be produced by certain narcotic agents, which make the patient even more sluggish than does carbon dioxide. Our present knowledge of the mechanism acting in bringing about these results is too vague to permit us to harmonize them with the other observations which we have quoted.

We now come to the question of possible interpretation and explanation of the data already at hand with respect to the rôle of the acid-base equilibrium in connection with personality. The most widely accepted view makes respiratory sluggishness the prime factor in the picture. According to this view, the person who fails to breathe properly because of lowered activity (or perhaps a lowered threshold) of the respiratory centre is unable to eliminate carbon dioxide properly. His alveolar air shows a high percentage of this gas. His urine is acid, because the urinary mechanism must help to maintain the balance. His saliva tends toward acidity. In addition, he may be emotionally flat, apathetic or even lethargic. We must postulate, therefore, that retained carbon dioxide acts as a drug, a depressant of cortical and thalamic activity.

Another theory, that of Armstrong, ${ }^{16}$ is that the carbon dioxide in the blood plasma regulates the flow of chlorides from the plasma to the corpuscles and vice versâ. When a normal person awakes and increases his respiratory ventilation there is increased excretion of chlorides in the urine. But in psychotics there is retention of chlorine, and in catatonics an actual reversal of the chloride shift, because their pulmonary ventilation is greater in sleep than while awake. Further data are desirable before we can evaluate these findings. More detailed study of chloride metabolism is indicated as a direction for future research in this field.

\section{CREATININE}

In connexion with the above considerations, we may next turn our attention to the relations of creatinine metabolism to personality charac- 
teristics. It is commonly accepted in biochemistry that creatinine is a product of muscular metabolism and that the amount of it formed and excreted depends upon the size and development, but not the activity, of the muscular system. This point of view naturally turned the attention of psychiatrists to the study of creatinine in connection with patients who show disorders in activity. But when Weinberg ${ }^{17}$ investigated the creatinine output of patients with neuromuscular diseases he was led to the conclusion that such variations as he found were due not to the disturbances in muscular tonus, but to mental influences. Soon afterwards Looney ${ }^{18}$ found marked increases in the creatinine content of the blood of catatonic patients, while Stratton ${ }^{19}$ reported a detailed study of the changes in the creatinine excretion of a sub-breathing stammerer under treatment and in relapses.

Working, as before, with personality differences which are within the range of normality, we have found a relationship of emotional excitability to creatinine production somewhat parallelling that to body acidity. Our correlations ${ }^{13}$ show that the most excitable persons tend to have both the lowest concentration of creatinine in the blood and the smallest relative amounts of excretion of creatinine in the urine. These results fit in with the observations on the stammerer and also with the findings in catatonics, since the latter condition may be considered as one of decreased liability to emotional response.

It is rather interesting that both creatinine excretion and urinary acidity tend to vary with the person's state of emotional lability. But it is not so surprising when one notes, as we ${ }^{20}$ have shown elsewhere, that these two urinary measurements have a high tendency to vary concomitantly. This relationship opens several possibilities of explanation. Are the variations in creatinine output entirely secondary to those in the acid-base equilibrium ? Does the state of the central nervous system profoundly affect muscular metabolism ? Should we speak of personality, considered as gross patterns of behaviour, as dependent upon the condition of the neuromuscular system rather than that of the nervous system ? Or must we consider the relationship as one due to the action of creatinine as a drug which modifies behaviour ? The answers to these questions are still in the future.

\section{PHOSPHORUS}

The relation of phosphorus to mental activity has long intrigued the popular mind. Yet it appears to have been of little interest to the scientists. There have been a few observations on the phosphorus excretion of psychotics, with almost uniformly negative results. A striking exception is the work of Folin and Schaefer, ${ }^{21}$ who studied a single case of manic-depressive insanity and found a consistent alternation of the nitrogen-phosphate and sulphatephosphate ratios in the urine as between normal and disturbed periods. They attributed the difference to an abnormality in the assimilation of the phosphorus. More recently Powers ${ }^{22}$ has claimed to find an increase above 
the normal in the phosphorus content of the blood of idiots, but another experimenter, Negus, ${ }^{23}$ has failed to find this difference.

Our own experiments ${ }^{13}$ have produced markedly' discordant results with respect to phosphorus. Thus the personality characteristic of goodnaturedness correlates positively with the urinary excretion of phosphorus and negatively with the amount of phosphorus in the blood. Nor did a more detailed study ${ }^{24}$ of the various types of phosphorus in the blood clarify the situation, but, on the contrary, added to the confusion. Even the most marked correspondence, i.e., the highest correlation, found in the entire experiment, which was between intelligence and phosphorus excretion, was determined in so small a group as to be of doubtful significance. Although it is in accord with the findings of Powers in the case of the blood phosphorus of idiots, as mentioned above, our figures for the phosphorus of the blood agree with neither. These fragmentary and contradictory results make it impossible to come to any conclusion as to the relation of phosphorus to personality traits, but they do suggest-further study of the subject.

\section{GALGIUM}

A number of recent investigations of the effect of various ions upon living tissue, and particularly upon the peripheral nerves, has aroused interest in the rôle of calcium. Yet it is surprising to find that as yet no relationship between personality and the calcium content of body fluids has come to light. The few studies of persons with mental disease yield nothing that is consistent. The experiments ${ }^{24}$ upon normal individuals have not shown correlations between the calcium of the blood and such personality traits as goodnaturedness, aggressiveness, emotional excitability or intelligence of sufficient size to be considered reliable. Here, again, further study is indicated.

\section{CONGLUSIONS}

No attempt has been made in this paper to make a comprehensive survey of all the studies which relate personality, normal or abnormal, to the chemical activity of the body. Thus the growing literature which links up blood-sugar curves, basal metabolism, nitrogenous constituents and products of the body, and, quite recently, colloid chemistry to behaviour has not been touched upon. We have considered in some detail four typical biochemical conditions and their relations to personality. In the case of acid-base equilibrium and creatinine production, it would seem that at the present time sufficient observations, obtained by various methods and from various points of view, are now at hand to enable us definitely to relate both of these chemical factors to the individual's emotional excitability. Much, of course, remains to be done. As has been already noted, in neither case is the explanatory interpretation clear. The choice between various hypotheses must await further facts. Nor are all the facts as yet unequivocal. In the case of phosphorus, the results which have been obtained as yet are so discordant 
as to lead to no rational interpretation of any consistent relationship. Yet they are sufficiently suggestive to incite one to further investigation. Finally, we noted that calcium, which a priori would have been expected to yield significant results, has led only to negative findings.

With these facts in mind, one may well ask whether or not investigations of the sort which we have quoted are worth while. At first sight it seems that the positive results are meagre. But it must be remembered that research in this field is quite new, and that few workers have been engaged in it. Moreover, the field is tremendous in extent and only a few of the many possibilities have even been touched upon. If these considerations are kept in mind, the situation seems somewhat different. The findings are not really so few in proportion to the amount of work done. They compare, from this point of view, not so unfavourably with those obtained by workers who have followed the other lines of psychobiochemical investigation mentioned at the beginning of the paper, not to mention the non-chemical field of endeavour in physiological psychology. It is, perhaps, permissible to conclude with a feeling of optimism as to the future of research into the relations of personality to body chemistry.

\section{REFERENGES}

1 Ludlum, S. D., ' Physiologic psychiatry,' Med. Clin. of North Amer., 1918, 2, 895.

2 Ludlum, S. D., 'Clinical psychiatry,' New York Med. Jour., 1922, 116, 459.

3 Ludlum, S. D., and McDonald, E., 'Mechanisms of disease : Preliminary communication,' Med. Jour. and Record, 1925, 121, 589.

4 McDonald, E., 'Age and the equilibrium of life,' Med. Jour. and Record, 1927, 126, 346.

${ }^{5}$ Starr, H. E., ' The hydrogen-ion concentration of mixed saliva considered as an index of fatigue and of emotional expression, and applied to a study of the metabolic etiology of stammering,' Amer. Jour. Psychol., 1922, 33, 394.

- Starr, H. E., 'Psychological concomitants of high alveolar carbon dioxide, a psychobiochemical study of the etiology of stammering,' Psychol. Clinic, 1928, 17, 1.

7 Trumper, M., 'The function of the psychobiochemistry laboratory,' Psychol. Clinic, 1929, 18, 192.

8 Mann, S. A., Morris, R. W., and Rowe, G. K., 'Studies on the acid-base regulation in mental disorders : I. The determination of urinary acidity,' Jour. of Ment. Sci., 1928, 74, 425.

- Mann, S. A., and Marsh, R. G. B. 'Studies on the acid-base regulation in mental disorders : II. The significance of urinary reaction in psychotic subjects,' Jour. of Ment. Sci., 1928, 74, 436.

10 Golla, F., ManN, S. A., and Marsh, R. G. B., 'Studies on the acid-base regulation in mental disorders : III. The respiratory regulation in psychotic subjects,' Jour. of Ment. Sci., 1928, 74, 443.

11 Golla, F., 'Some recent work on the pathology of schizophrenia,' Jour. of Ment. Sci., 1929, 75, 661.

12 Marsh, R. G. B., ' The excitability of the respiratory centre of psychotic patients,' Lancet, 1929, $2,1032$.

13 Rich, G. J., 'A biochemical approach to the study of personality,' Journ. Abnorm. Soc. Psychol., 1928, 23, 158. 
14 Rich, G. J., ' Body acidity as related to emotional excitability,' Arch. Neurol. and Psychiat., 1928, 20, 589.

15 Freeman, W., 'Psychochemistry,' Journ. Amer. Med. Assoc., 1931, 97, 293.

16 Armstrong, R. W., 'Investigation into distribution of chlorine in blood and urine in certain types of mental disorder,' Jour. of Ment. Sci., 1929, 75, 644.

17 Weinberg, A. A., 'The influence of the nervous system on the excretion of creatinine,' Biochem. Jour., 1921, 15, 306.

18 Looney, J. M., 'The relation between increased muscle tension and creatine,' Amer. Jour. Physiol., 1924, 69, 638.

19 Stratten, L. D., 'A factor in the etiology of a sub-breathing stammerer : Metabolism as indicated by urinary creatinine and urinary creatine,' Jour. Compar. Psychol., 1924, 4, 325.

${ }^{20}$ RICH, G. J., 'A relationship between phosphorus, creatinine and acidity in urinary excretion,' Proc. Soc. Exper. Biol. and Med., 1928, 25, 307.

${ }^{21}$ Folin, O., and Schaefer, P., ' On phosphorus metabolism,' Amer. Jour. Physiol., 1902, $7,135$.

${ }^{22}$ Powers, H. D., 'Biochemistry in relation to intelligence,' Science, 1931, '73, 316.

${ }^{23}$ Negus, S. S., 'Analyses of the blood of idiots,' Science, 1931, 73, 449.

24 Rich, G. J., 'Intelligence and body chemistry,' Science, 1931, 74, 21. 